\title{
Integration of GeoGebra in Teaching and Learning Geometric Transformations at Ordinary Level in Zimbabwe
}

\author{
Edmore Mukamba $^{1}(\mathbb{D})$, Chipo Makamure ${ }^{2 *}$ (1)
}

${ }^{1}$ Gilston Secondary School, ZIMBABWE

${ }^{2}$ University of South Africa (UNISA), SOUTH AFRICA

*Corresponding Author: makamburec@gmail.com

Citation: Mukamba, E., \& Makamure, C. (2020). Integration of GeoGebra in Teaching and Learning Geometric Transformations at Ordinary Level in Zimbabwe. Contemporary Mathematics and Science Education, 1(1), ep20001. https://doi.org/10.30935/conmaths/8431

\begin{abstract}
The performance of learners in 'O' level mathematics has been generally poor in Zimbabwe. There is evidence that learners have challenges in understanding and interrelating Geometric Transformation concepts as they are used in mathematics. Inappropriate pedagogical strategies of teaching the topic are viewed as the main causes of the problem. This backdrop prompted the authors to enquire the effectiveness of GeoGebra as a pedagogical tool in teaching and learning Geometric Transformations (GT) at 'O' level, as contrasted to traditional teaching methods used by most classroom practitioners. A real classroom set up involving the control and experimental groups of learners was used to carry out the study. The mixed methods approach used, incorporated semi-structured interviews for mathematics teachers, while written pre and post tests for both groups of learners were administered. The outcomes of this study show that although the traditional methods had a positive impact on learners' performance, the use of GeoGebra improved their performance more in GT. Based on these findings the study recommends that for effective and quality learning in GT, teachers should embrace virtual manipulatives to conduct mathematics instruction as it is likely to enhance the mastery and retention of concepts as reflected in the study.
\end{abstract}

Keywords: GeoGebra, ICT, geometric transformations, visualisation, teaching

Received: 3 Jun. $2020 \bullet$ Accepted: 1 Jul. 2020

\section{INTRODUCTION}

Geometric transformations (GT) is a mathematical topic that involves alterations of objects somehow, either in position or shape. According to Kekana (2016), GT consist of movements such as rotation, translation and reflection and also with dilations or shrinking and enlargement. For example, an object can be moved from point $A$ to point $\mathrm{B}$, thus, the object has changed its position. GT is a topic that is included in the Zimbabwean $O$ level curriculum. It is considered important because it holds a practical application in the education curriculum and in real life situations. Learners are normally involved in hands-on activities with tangible objects. The hands-on practice improves learner motivation and participation in the teaching and learning of GT. The Zimbabwe School Examination Council (ZIMSEC) examiners' reports for (2004-2018) also indicate 'GTs' as the most attempted topic by learners in the final examinations in Zimbabwe. This report is evidence that this component of mathematics is popular to both learners and mathematics educators.

However, despite the popularity and importance of GT in education, Zimsec Reports (2004-2018) show that among other components of mathematics, the topic has the least pass rate at $\mathrm{O}$ level in Zimbabwe. The reports indicate that most students do not perform well in 'shearing and stretching of geometrical shapes. In the same vein, Haggart (2002) and Jaji (1990) affirm that most students taking mathematics worldwide, at the basic secondary level were found to have difficulties in understanding GT concepts. According to a study by Shadaan and Eu (2013), it was also discovered that learners have difficulties in learning aspects that are linked to GT. Soon, (1989) claims that teachers have challenges in teaching GT in a way that stimulates curiosity and motivation among learners. These challenges may breed negative attitudes towards the topic, which may culminate into phobia. Haggart (2002) concurs with Jaji (1990) who affirms that learners' challenges with GT are merely pedagogical, and failure can be attributed to the teaching approaches employed and availability of teaching facilities. The ministry of Primary and Secondary Education in Zimbabwe and other stakeholders are of the view that an intervention to enhance the learners' performance in the subject is necessary. The Nziramasanga Commission of Inquiry into the Zimbabwean Education (1999) reports that mathematics was in crisis due to the high failure rate. This discovery led to the review of the Zimbabwean mathematics curriculum so that ICT can be integrated into the mainstream curriculum. The idea being that if ICT is incorporated into the curriculum, it will improve the learner's interest and performance. The purpose of this study is therefore to explore the effects of using Geogebra (GG) in teaching and learning GT at Ordinary level in 
Zimbabwe. The study is therefore guided by the following research question: What impact does GeoGebra have on the internalisation and conceptualisation of GTconcepts by O level learners in Zimbabwe?

\section{STATEMENT OF THE PROBLEM}

Regardless of the significance placed on GT as a topic in the Zimbabwean 'O' level mathematics curriculum, the problem of high failure rate in the learning aspects linked to GT remains unabated. Literature revealed that failure in this topic is normally pedagogical and that the failure rate is attributed to the teaching approaches employed by the teachers, as well as the availability of teaching facilities in the schools. In order to address the problem of poor performance in GT, this study seeks to explore the effectiveness of GG Instruction Software over the traditional methods, in teaching and learning GT at ' $\mathrm{O}$ ' level in Zimbabwe.

\section{LITERATURE REVIEW}

\section{Transformation Geometry: What it Entails}

GT comprises components such as translation, reflection, rotation (Akay, 2011), and also stretching, shearing and enlargement (dilation). GT is defined by Pleet (1990) as the study of figures and their properties. The study of GT allows learners to recognise and perform changes in the coordinates of objects in relation to their images regarding their position, orientation, direction and size, (Kekana, 2016). According to the Zimbabwean school curriculum, GT as a topic is taught at form 4 level.

The inclusion of geometry in the 'O' level mathematics syllabus has been a way of providing learners with a foundation for geometrical conception, but learners performance in this area has been generally poor (ZIMSEC, 2004- 2018). This has been noted by Zimsec examiner's reports during the same period. The reports indicate that learners are not benefiting from the methods used to teach the concepts of GT. The reports are also supported by Wesslen and Fernandez (2005) who point out that GT is not only difficult for primary school leaners but also secondary school learners struggle with the topic. According to Haggart, (2002), failure in geometry and other related topics is due to the little appreciation that teachers render to the learner's backgrounds in relation to the content taught. Appreciation of learners' background could mean that teachers have to consider the learners' previous learning experiences before introducing a topic in GT so that they meet the learners' needs in teaching the content. A study by Denis and Livia (1987) revealed that $74 \%$ of high school learners failed to meet the requirements of traditional secondary school geometry. The above findings were also supported by other studies by Hollebrands (2003), Soon (1989), Ada and Kurtulus (2010). These investigations looked into the learner's ability to understand concepts of geometry. The results showed that learners had challenges.

Ada and Kurtulus' (2010) study revealed that there were misconceptions among learners regarding rotational transformation. It was observed that the learners seemed to understand the meaning of translation and rotation algebraically whilst the geometrical meaning of these concepts was not fully mastered. The results point to the need to improve strategies of teaching GT, so that learners are exposed to technological tools that enhance understanding of key concepts in GT.
Thus, this study seeks to ascertain the impact of ICT, GG in particular, on teaching and learning GT.

\section{ICT As a Visual Tool to Teach and Learn GT}

The integration of technology and e-learning in mathematics education has been a topical issue in recent studies. According to the NCTM (2000), technology has become one of the key principles to enhance quality learning in mathematics. As such, learners are expected to develop several competences for them to work effectively in this technology-driven education (Mnguni, 2014). Hoong and Khoh (2003) contend that since "Geometric Transformations" is a visual topic, the utilisation of ICT software which aid visualisation could have a positive effect on learners' understanding of the topic. In addition, Idris (2006) identified the causes of difficulties in Geometry learning as visualization abilities and ineffective instruction. According to Vasquez (2015) visual learning is a powerful tool as it involves skills such as observation, recognition, interpretation, perception and self-expression. These skills provide the learner with the opportunity to see, examine something and then to visually recall and interpret information leading to comprehension and understanding of mathematical concepts (Vasquez, 2015). Similarly, Murphy (2009) reiterated that with visual tools, learners are able to analyse concepts, make conjectures and convey ideas to others (externalization of ideas). These attributes of visualization point to the fact that the attention of the learners is easily grabbed, hence, engage them in their learning. All the ideas about visualization are confirmed by Edgar Dale's (1969) theory which theorized that people understand $20 \%$ of what they hear, $50 \%$ of what they see and hear and $90 \%$ of what they do as a task. The use of visual technology in the classrooms therefore, seems to provide learners with clear explanations and illustrations which could benefit learners to explicitly understand mathematical concepts. However, the use of visuals is critical since most educators teach students to memorise and recall information instead of understanding concepts efficiently (Vasquez, 2015). A study conducted by Kulik and Kulik (1987) established that a computer-based instruction was considered to have positive effects on learners studying mathematics. The significance of using computers in mathematics teaching has also been advocated by the NCTM (2000) and Bansilal (2015) when they assert that the global technological developments have affected all facets of life, including classroom mathematics teaching and learning. Similarly, Ogwel (2009) emphasised that there is a coherent urge to align education with technology since society is rapidly changing. This explains that ICT is pivotal during instruction as it links theory with practice, thus, enabling learners to grasp the content taught. With the importance placed on technology, it is necessary that teachers be conversant with the use of ICT in teaching and learning mathematics. Several studies have unearthed some barriers to using ICT in the classroom. Some of these barriers are lack of training among teachers, hence lack of confidence to use ICT during integration (Seloraji \& Eu, 2017). However, the need to promote critical thinking, social interaction and a holistic understanding of students learning experiences has provoked the incorporation of technology in the mathematics classroom (Shadaan \& $\mathrm{Eu}, 2013)$. Hence, the purpose of the study is to determine the influence of GG software on students' performance in GT.

\section{GeoGebra as an ICT instrument to Teach GT}

According to $\mathrm{Bu}$ et al (2011, p15), GG "is open source and thus is freely available to the international community", hence Ogwel (2009) encourages the incorporation of the software to teach Geometry. 


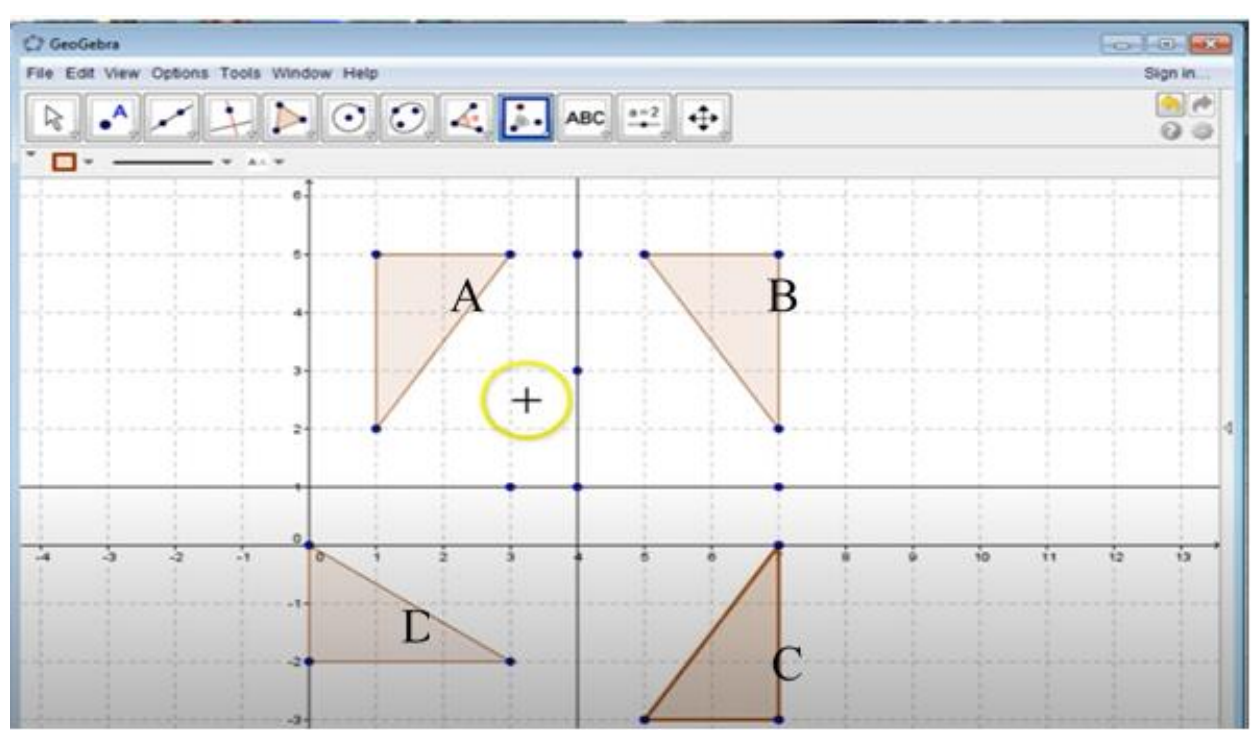

Figure 1. Extracted from: GeoGebra Tutorial - Transformation Geometry by Billman C (2014)

Hohenwarter and Preiner (2007) view GG as a mathematics flexible tool which enhances visualisation of mathematical ideas at all levels of learning. The visualization enhanced by GG software thus, provides learners with a clear view of both simple and complex mathematical constructions. According to Hohenwarter and Lavicza (2007), GG software was created to bring learners' conceptual gaps in understanding geometry and algebra. This implies that, the creation of GG was mainly a solution to conceptual challenges faced by learners in geometry and algebra in general. Many studies have demonstrated that GG is helpful in improving learners' achievement in learning mathematics (Nazihatulhasanah \& Shukor, 2015; Shadaan \& Eu, 2013), and that the software develops creativity among mathematically gifted learners (Korenova, 2012). Dogan (2010) concurs that GG encourages higher order thinking skills and that it has a positive effect on learners' retention of knowledge. However, the use of GG to teach mathematics is a challenge to teachers due to lack of training in the use of technology (Davidson, Richardson \& Jones, 2014; Alharbi, 2013). The lack of training is due to insufficiency of computers and other necessary devices to implement ICT-integrated lessons (Arienda et al, 2016). By and large, most scholars (Herceg \& Herceg, 2010; Bakar, Ayub, Luan \& Tarzimi, 2002) agree that GG is a tool that is instrumental to the teaching and learning of mathematics in general and Geometry in particular. The example below confirms what Murphy (2009) posed, that with such tools, learners are able to analyse concepts and make conjectures and convey ideas to others (See Figure 1).

The picture is a screen showing GG being used to transform an object (triangle A). A click of the button will draw the reflection lines, transfer and rotate the object, which suggests that the use of GG is fast and convenient to the learner. In this instance, triangle $\mathbf{A}$ has been reflected twice, first through the line $\mathrm{x}=4$ to get image $\mathbf{B}$ and then through the line $\mathrm{y}=1$ to get the image $\mathbf{C}$. All this is easy to manipulate as long as the problem solver clicks the correct information on the system. It is clear to the learner, through experiment and hands-on practice on the screen, that triangle $\mathrm{A}$ is rotated $180^{\circ}$ about the point $(4,1)$, to get the image $\mathbf{C}$. So, in this respect, the learner can discover and conclude that two reflections through the two lines are equal to a single rotation of $180^{\circ}$ about the point $(4,1)$-Conjecture.
However, despite that GG is instrumental and widely used, it is critical that its influence in mathematics instruction be further investigated (Freinman, Martinovic \& Karadag, 2010), especially in Zimbabwe where the software is not very popular. Hence, this study attempts to establish the impact of GG in the teaching and learning of mathematics at ' $\mathrm{O}$ ' level in Zimbabwe.

\section{THEORETICAL FRAMEWORK}

This study is undergirded by the theory of Realistic Mathematics Education (RME) (Freudenthal, 1978; Gravemeijer, Cobb, Bowers, \& Whitenack, 2000). Since the study is about the impact of GG on students' performance in GT, it fits well in the tenets of RME because $\mathrm{RME}$ is grounded in the realistic connections of mathematical ideas $(\mathrm{Bu}$, Spector \& Haciomeroglu, 2011). According to $\mathrm{Bu}$, Spector \& Haciomeroglu (2011), RME considers mathematics learning as a human activity and as a process of guided reformulation of mathematical ideas through horizontal mathematisation. In horizontal mathematisation, Bu et al (2011) assert that real world problem situations are symbolized by mathematical models, which resonates with the topic under study. In short, horizontal mathematisation is simply transforming daily problems to mathematics symbols. Similarly, Clements and Sarama (2013) state that RME includes the development of a model which allows learners to associate problems with contexts, identify relevant mathematical concepts, solve problems, and interpret the solution on the basis of their contexts. Viewed from the theoretical lenses of RME, GG is a tool that allows learners to mathematise realistic problem situations, and experiment with some models using multiple representations to formulate abstract mathematical ideas $(\mathrm{Bu}$, Spector \& Haciomeroglu, 2011). The visual model, which is demonstrated in GG can generate problem solving skills in the learners, which they can use to solve realistic problem situations. Laurens et al (2017) contends that RME starts with problems relevant to learners' experiences and knowledge. The teacher then facilitates to assist learners to solve the contextual issues. This problem-solving activity breeds positive impact to the learners' cognitive achievement that is related to their understanding of mathematics. This means learners can be best taught mathematics by asking them to mathematically solve problems that they 
experience on a daily basis, hence, improving their creative thinking. Laurens et al (2017) concurs that mathematics is not only for academics, but is involved in one's daily life. Thus, mathematics, according to the RME theoretical framework, constitutes a process where learners mathematically formalise their informal understanding and intuition.

\section{METHOD}

\section{Research Approach and Design}

A mixed methods approach was used to collect data for this study. The study incorporated a quasi-experimental design in collecting quantitative data from pre and post-tests. The non-equivalent quasiexperimental design was used because classes of unequal number of learners were used and the respondents were not randomly selected and allocated to the groups (Creswell, 2008). Hence, in this study, the selection of subjects was purposive. The study purposively targeted 2 'O' level mathematics teachers and 54 form four learners, because GT is an 'O' level topic in the Zimbabwean curriculum and participants were assumed to be able to provide the information requested by the authors. However, qualitative approach in form of semi-structured interviews with teachers was also utilised to answer some of the questions where quantitative methods would not suffice.

\section{Participants}

The participants in the study were Form four students at a school under the pseudonym $\mathbf{D}$ in Zimbabwe. "Form four" is a 4-year course for learners in high school. It is the exit point for those learners that do not intend to proceed to University but can train for other professional qualifications such as a diploma in teacher education. Two classes A and B with 28 and 26 learners respectively were considered for the study. All the participant learners were being taught mathematics by the same teacher. Class A was chosen as the experimental group whilst B was the control group of the study. GG was used for class A to teach GT whist the control group was conducted using other traditional methods such as the demonstration method. The 2 mathematics teachers selected for the study interviews were also teaching mathematics upto $\mathrm{O}$ level but were not directly involved in teaching the two classes in the study. The two of them were graduate teachers with a Bachelor's degree in mathematics education.

\section{Data Collection Procedures}

\section{Quantitative data}

A quasi-experimental design was used to collect quantitative data In the quasi-experimental design, the independent variable (treatment) in the study was the teaching methods used in teaching GT, whilst the learners' performance was the dependent variable. The definition implies that the treatment administered is tested for how well it achieves its objectives (Mutendi \& Makamure, 2019) as determined by the difference of performance in the two groups where one group was taught using GG and the other one was engaged in traditional methods. In applying the quasi-experimental design, White and Sabarwal, (2014) outline that the researcher selects the sample of subjects, determines the treatment, decides which groups to receive the treatment, controls other variables other than the treatment and ultimately, assesses the effect of the treatment on the groups. Hence, the two classes (A \& B) of learners were selected and the participants wrote the same achievement test (Post Test) after being taught the same topic using different methods.

The researcher first gave learners from both classes A and B, a pretest so as to establish learners' readiness for learning GT. The pre-test determined the initial entry points and compared differences between the two groups before treatment. Hence, the test was meant to establish and confirm that the two groups were at the same level in terms of their understanding of GT. From the two groups involved in the study, group A, with 28 learners was taught using GG software whilst group B with 26 learners was taught using the other traditional methods of teaching. The traditional methods used were; the demonstration method, question and answer method, and chalk and board teaching method. Afterwards, a teacher-made written post-test, based on the topic of GT, was administered to find out how learners performed after learning Geometry using or without using GG. The post-test was meant to ascertain the impact and effectiveness of GG in teaching and learning GT. In this study, the authors preferred a teacher-madeachievement post-test to other types of tests because it reflects instruction and curriculum, it is sensitive to learner's ability and needs, it provides immediate feedback about learners' progress and it can reflect small changes in knowledge (O'Malley, 2010). The items on the teacher-made achievement test were therefore constructed on the basis of the lesson taught and the learning objectives in the ' $\mathrm{O}$ ' level mathematics curriculum. The aim of this instrument was to provide a measurement of achievement. The post-test results of the two groups established whether the outcome and/or dissonance was related to the treatment. All the 54 learners wrote the post-test that was later analysed. Questions for the post-test were extracted from ZIMSEC past examination papers because the papers gave a standard of the level of questions that is required for ' $\mathrm{O}$ ' level learners in Zimbabwe.

\section{Qualitative data}

In the study, the authors used semi-structured interviews (SSI) to collect data from two 'O' level mathematics teachers at school $\mathbf{D}$ in Zimbabwe. The teachers were interviewed to ascertain their perceptions regarding the teaching and learning of GT in general and how often they utilised ICT to teach GT at 'O' level. The interviews were conducted on a one to one basis over two days. The researcher made use of audio and field notes to record both verbal and non-verbal responses.

\section{Data Analysis Procedures \\ Quantitative data}

Both inferential and descriptive statistics were used to analyse quantitative data. Frequency tables of the pre-test for the two classes A and $\mathrm{B}$ were drawn and respective percentages and means were calculated and compared. The comparison was done to establish the entry points of the participants in order to alleviate bias after the treatment. The means were compared to ascertain whether the participants were starting from the same level, to improve the validity of the results. The significant difference on the pre-test written would mean changing the population so that similar groups in terms of performance are considered for the study.

The means of the post-test for classes A and B were also calculated and compared using the two tailed t-test to find out whether there was a significant difference between them. The means were compared at $5 \%$ level of significance. Since the learners were of comparable ability, a significant difference in performance of the post-test may be attributed 
Table 1. Learners' Performance in Pre-test

\begin{tabular}{|c|c|c|c|c|c|c|c|c|}
\hline Learners Score (Out of 40) & & $0-9$ & 10-19 & $20-29$ & $30-39$ & 40 & Mean Mark & TOTAL (N) \\
\hline \multirow{2}{*}{ Frequency } & CLASS A & 20 69\%) & $7(25 \%)$ & $1(3 \%)$ & $0(0 \%)$ & $0(0 \%)$ & $8.68 \%$ & 28 \\
\hline & CLASS B & $1350 \%)$ & $11(32 \%)$ & $2(8 \%)$ & $0(0 \%)$ & $0(0 \%)$ & $9.35 \%$ & 26 \\
\hline
\end{tabular}

Table 2. Learners performance in post-test

\begin{tabular}{ccc}
\hline Learners' scores (Out of 40) & \multicolumn{2}{c}{ Frequency \& Percentage } \\
\hline $0-9$ & Class A (GeoGebra) & Class B (Traditional) \\
\hline $10-19$ & $0(0 \%)$ & $20(77 \%)$ \\
\hline $20-29$ & $2(7 \%)$ & $14(50 \%)$ \\
\hline $30-39$ & $12(43 \%)$ & $1(4 \%)$ \\
\hline 40 & $0(0 \%)$ & $0(0 \%)$ \\
\hline TOT AL (N) & 28 \\
\hline Mean Mark & $27.4(68.5 \%)$ & $18.42(46 \%)$ \\
\hline
\end{tabular}

Table 3. Analysis of Pre and Post-test

\begin{tabular}{cccccc}
\hline & Number of participants (N) & Pre-Test mean & Post-Test mean & Difference/increase (\%age) & Method used for the Post Test \\
\hline Class A & 28 & 8.68 & 27.4 & $215.7 \%$ & GeoGebra \\
\hline Class B & 26 & 9.35 & 18.42 & Traditional & $97 \%$ \\
\hline
\end{tabular}

Table 4. Testing the Difference between the Post Test means for classes A and B

\begin{tabular}{cccc}
\hline & Class A & 28 & 26 \\
\hline $\mathrm{N}$ & 27.39 & \\
\hline Mean $\left(\mu_{1}, \mu_{2}\right)$ & 5.74 & \\
\hline Standard deviation (SD) & 4.39 & \\
\hline t-experimental & 6.414 \\
\hline P(type 1 error) & .000000038 \\
\hline
\end{tabular}

Notes $^{*}$ : Class A - Data after treatment (GeoGebra), Class B- Data after treatment (Traditional)

to the treatments used in the study. The result of the t-test was followed by a verbal analysis of the outcome. For ethical reasons, all the names displayed in the presentation and analysis of data are pseudonyms.

\section{Qualitative data}

Textual data from the interviews was interpreted and analysed verbally together with the quantitative data.

\section{RESULTS, ANALYSIS AND DISCUSSION}

\section{Introduction}

This study investigated the effectiveness of GG Instructional Software on learners' conceptual understanding of GT in secondary school mathematics. The teacher-made achievement test (post-test) gave meaning to the results of the findings of this study.

\section{Analysis of the Pre-Test}

Learners in both classes A and B wrote a one-hour pre-test to ascertain their level of understanding before treatment. The pre-test was marked out of 40 . The scores obtained by learners in the pre-test for classes A and B were examined and compared in Table 1.

Results of Table 1 show that the means are almost the same and that there is no significant difference between the two means for classes $\mathrm{A}$ and $\mathrm{B}$, hence the two classes performed at the same level before treatment. This entails that the treatment (Post Test) was applied on students who were at the same level of understanding Geometry, which is likely to enhance the validity of the results.

\section{Analysis of the post-test}

Table 2 shows the results of the post-test written by the two groups $\mathrm{A}$ and $\mathrm{B}$.

Table 2 illustrates the post-test scores of the learners in both classes A and B. GG was used to teach geometry to class A whilst class B was taught the same topic using the traditional methods. The results show that after the use of GG, $93 \%$ of the learners in class A managed to score marks above $50 \%$. The general performance of learners in ' $\mathrm{A}$ ' improved as evidenced by the increase in the mean scores from 8.68 to 27.4 out of 40. As for the control class B, there were also signs of improvement from the pre-test to the post test. The average mark rose from 9.35 for the pre-test to 18.42 for the post test. By and large, the difference between the pre and post-tests scores for both classes shows that both methods had a positive effect on the learners' understanding of the topic as shown in Table 3.

Table 4 tests the difference between the post- test means of the two classes A and B.

$\mathrm{H}_{0}: \mu_{1}=\mu_{2}$ where $\mathrm{H}_{0}$ is the Null hypothesis

$\mathrm{H}_{1}: \mu_{1} \neq \mu_{2}$ where $\mathrm{H}_{1}$ is the alternative hypothesis

Since $p$ - value $=.000000038<0.05$, we reject $\mathrm{H}_{0}$ and conclude that there is no sufficient evidence at $95 \%$ confidence interval to claim that class A mean $\left(\mu_{1}\right)$ is equal to class B mean $\left(\mu_{2}\right)$. Hence, testing at the $5 \%$ level of significance, the $t$-test results confirm that there is significance difference between the two means. The difference could be ascribed to the teaching methods used to teach the topic. GG thus, seemed to have a bigger positive impact on the performance of learners in the post test than the traditional methods. This quantitative result confirms the 
results of the studies by Bakar, Ayub, Luan and Tarzimi (2002) and Nazihatulhasanah and Shukor (2015) that GG is helpful in enhancing learners' achievement in mathematics. The result is also confirmed by the teachers' responses during the interviews. It was quite conspicuous from the interviews that teachers liked the use of GG in lesson planning and presentations. The teachers clearly spelt out the positive impact of the software on learners' performance. The two teachers interviewed concurred that the software was very helpful in fighting misconceptions in GT among learners. They also indicated that they used the tool quite often during lessons because it motivates learners. A teacher, under the pseudonym Tanaka, one of the interviewees said:

I use GG for both lesson planning and presentation of GT lessons because the topic requires learners to visualise and manipulate the objects.........since $G G$ is free and user friendly, it makes drawings very clear and neat unlike on the chalkboard. I would surely recommend it to both mathematics teachers and learners because GT problems are solved very fast and comprehensively, and students enjoy the use of $G G$. To them, it's a new thing.....

In addition to using the software in the classroom, Tanaka also reiterated that he would not mind recommending the use of this tool to other members teaching mathematics. Tanaka's responses resonate with Hohenwarter and, Preiner's (2007) view that GG is a mathematics tool which is flexible and that it enhances visualisation of mathematical concepts. Thus, the software provides learners with a vivid view of both simple and complex mathematical constructions (Hohenwarter \& Preiner, 2007)

Dennis, another mathematics teacher interviewed had this to say also;

GG saves time, learners can have a clear view of what I want to teach them. It is easy for learners to visualise all the teacher's explanations and requirements. Using the software, learners are able to fully describe all the transformations applied on an object to get its image. Students really like GG........

The two teachers also explained how quick it was to solve GT problems using GG. In addition, learners had an understanding of finding matrices of various transformations by hands-on practices on the computer screen without memorising them. Above all, both teachers mentioned the enjoyment students have when learning using GG. Shadaan and Eu (2013) study revealed that GG improves students' motivation to learn mathematics and that their knowledge retention is sustained for a longer period. Students motivation implies that the learners have confidence and self-efficacy (Makamure, 2018). High selfefficacy is important because it signifies engagement and positive regard for school work. The fact that learners in the study did not memorise formulas and GT matrices, in the process of learning GT confirms what Dogan (2010) asserted, that GG software encourages higher order thinking skills among learners. Apart from being able to promote deep understanding of mathematical concepts, Tanaka and Dennis like the idea that GG is a free software thus, making it convenient and affordable for needy teachers and learners.

\section{CONCLUSION AND RECOMMENDATIONS}

Although some teachers believe that the most effective way to teach mathematics is to be patient, to repeat, drill and kill, explore, explain and give lots of class exercises", (Stols \& Kriek, 2011,); empirical evidence from this study show that the use of ICT, GG in particular, enhances the conceptual understanding of GT over the other traditional teaching methods (Table 4). In addition, it was evident from the interviews that GG enhances and improves learner visualisation, makes lessons practical, interesting and encourages understanding of concepts rather memorisation of theorems. This entails that GG can be the way forward in solving the problem of high failure rate in GT at $\mathrm{O}$ level in Zimbabwe. The findings of the study support the findings of Zengin, Furkan, Kutluca (2012) and Reis and Ozdemir (2010) that the use of dynamic software in geometry helps make the learning of mathematics abstract concepts easier than traditional teaching methods. The study thus, recommends that GG be fully utilised in the teaching and learning of GT concepts in secondary schools in Zimbabwe, so that learners' performance in this topic can be improved. According to Arienda et al (2016), the success of the GG-integrated mathematics lessons depends on the teacher knowledge to use the software. Hence, training is necessary for Mathematics teachers so that they become conversant with how the software is used. However, the training can be facilitated by the availability of necessary infrastructure and computer units. Future research on the impact of GG on students' performance can be conducted with a different topic other than GT.

\section{REFERENCES}

Ada, T., \& Kurtulus, A. (2010). Students' Misconceptions and Errors in Transformation Geometry. International Journal of Science and Technology, 41(7), 901-909. https://doi.org/10.1080/0020739X. 2010.486451

Akay, G. (2011). The effect of Peer Instruction Method on $8^{\text {th }}$ Grade students Mathematics Achievement in Transformation Geometry and Attitudes Towards Mathematics (Masters Thesis). Middle East Technical University.

Alharbi, A. M. (2013). Teacher's Attitudes towards Integrating Technology: Case Studies in Saudi Arabia and the United States (Masters Thesis). Grand Valley State University. Graduate Research and Creative Practice.

Arienda, A., Blas, A. L., Fulgencio, M. G., Laristan, S. D., \& Elipane, L. E. (2016). Identifying Advantages and Challenges of Integrating GeoGebra in Teaching Ellipse through Lesson Study. Proceedings of the 2016 KSME International Conference on Mathematics Education, Gyeonggi-do, Korea.

Bakar, K. A., Ayub, A. F. M., Luan, W. S., \& Tarmizi, R. A. (2002). Exploring secondary school students' motivation using technologies in teaching and learning mathematics. Procedia-Social and Behavioral Sciences, 14, 4650-4654. https://doi.org/ 10.1016/j.sbspro.2010.03.744

Bansilal, S. (2015). Exploring Student Teacher's Perceptions of the Influence of Technology in Learning Mathematics. South African Journal of Education, 35(4), 1-8. https://doi.org/10.15700/ saje.v35n4a1217

Billman, C. (2014). Reflection/Rotation/Translation Geogebra Available at: https://www.youtube.com/watch?v=iJ2RqNYjIVQ (Accessed: 24 May 2020). 
Bu, L., Spector, J. M., \& Haciomeroglu, E. S. (2011). Toward ModelCentered Mathematics Learning and Instruction using GeoGebra: A Theoretical Framework for Learning Mathematics with Understanding. In $\mathrm{Bu}, \mathrm{L}$. \& Schoen, R. (Eds.). Modeling and Simulations for Learning and Instruction: Model-Centered Learning Pathways to Mathematical Understanding Using GeoGebra (pp. 13-40). Rotterdam: Sense Publishers. https://doi.org/10.1007/978-946091-618-2

Clements, D. H., \& Sarama, J. (2013). Rethinking early mathematics: What is research based curriculum for young children? In L. D. English \& J. T. Mulligan (Eds.), Reconceptualizing early mathematics learning (pp. 121-147). Dordrecht: Springer. https://doi.org/ 10.1007/978-94-007-6440-8_7

Creswell, J. W. (2008). Educational research: Planning, conducting and evaluating quantitative and qualitative research. New Jersey: Pearson Prentice Hall.

Dale, E. (1969). Audio-visual methods in Teaching (3rd ed). New York: The Dryden Press. https://doi.org/10.1080/09523986908547873

Davidson, L. Y. J., Richardson, M., \& Jones, D. (2014). Teachers' perspective on using technology as an instructional tool. Research in Higher Education Journal, 24.

Denis, S., \& Livia, P. (1987). Relationship between stages of cognitive development and van Hiele levels of geometry thought among Pueto Rican adolescents. Fordham University.

Dogan, M. (2010). The role of dynamic geometry software in the process of learning: GeoGebra example about triangles. Retrieved from http:// www.time2010.uma.es/Proceedings/Papers/A026_Paper.pdf

Freinman, V., Martinovic, D., \& Karadag, Z. (2010). A Snapshot of GeoGebra Community Endeavours: Building a Research Agenda. Ithaca College: USA

Freudenthal, H. (1978). Weeding and sowing: Preface to a science of mathematics education. Dordrecht, Holland: D. Reidel.

Gravemeijer, K. P. E., Cobb, P., Bowers, J., \& Whitenack, J. (2000). Symbolizing, Modeling, and Instructional Design. In P. Cobb, E. Yackel, \& K. McClain (Eds.), Communicating and symbolizing in mathematics: Perspectives on discourse, tools, and instructional design (pp. 225-273). Mahwah, NJ: Lawrence Erlbaum Associates.

Haggart, L. (2002). Teaching Mathematics in Secondary Schools: A reader. London, The Open University.

Herceg, D., \& Herceg, D. (2010). Numerical integration with GeoGebra in high school. The International Journal for Technology in Mathematics, 17(4), 205-210.

Hohenwarter, M. \& Preiner, J. (2007). Dynamic mathematics with GeoGebra. The Journal of Online Mathematics and Its Applications, 7, 1448.

Hohenwarter, M., \& Lavicza, Z. (2007). Mathematics Teacher Development with ICT: Towards an International Geogebra Institute. In D. Kuchemann (Ed.), Proceedings of the British Society for Research into Learning Mathematics, 27, 3, 49-53.

Hollebrands, K. F. (2003). High school students' understanding of geometric transformations in the context of a technological environment. Journal of Mathematical Behavior, 22, 55-72. https://doi.org/10.1016/S0732-3123(03)00004-X
Hoong, L.C., \& Khoh, L.S. (2003). Effects of Geometres' Sketchpad on Spatial and Achievement in Transformation Geometry among Secondary Two Students in Singapore. Association of Mathematics Teacher, 7(1), 32-48.

Idris, N. (2006). Exploring the effects of T1-84 plus on achievement and anxiety in mathematics. Eurasia Journal of Mathematics, Science and Technology Education, 2(3), 66-78. https://doi.org/10.12973/ ejmste/75465

Jaji, G. (1990). The Teachers as an Implementor of the Curriculum in Zimbabwe Secondary schools. The Case of mathematics. Zimbabwe Journal of Educational research, 2(1), 1-24.

Kekana, G.R. (2016). Using GeoGebra in Transformation Geometry: An Investigation based on the Van Hiele Model (Dissertation). Faculty of Education, University of Pretoria.

Korenova, L. (2012). The use of A digital environment for developing the creativity of mathematically gifted high school students. 12th International Congress on Mathematical Education, Seoul, Korea.

Kulik, J. A., \& Kulik, C. L. (1987). Computer-based Instruction: What 200 evaluations say. Paper presented at the annual convention of the Association for Educational Communications and Technology, Atlanta, Georgia.

Laurens, F., Batlolona, F. A., Batlolona, J. F., \& Leasa, M. (2017). How Does Realistic Mathematics Education (RME) Improve Students' Mathematics Cognitive Achievement? EURASIA Journal of Mathematics, Science and Technology Education, 569-578. https://doi.org/10.12973/ejmste/76959

Makamure, C. (2018). Evoking Motivation for Achievement in Ó’ Level Mathematics in Zimbabwe. International Journal of Education (IJE), 6(4), 13-21. https://doi.org/10.5121/ije.2018.6402

Mnguni, L. E. (2014). The theoretical cognitive process of visualization for science education. SpringerPlus, 3(1), 1-9. https://doi.org/10.1186/2193-1801-3-184

Murphy, S. J. (2009). The power of visual learning in secondary mathematics education. Retrieved from https://assets.pearsonschool.com/asset_ mgr/legacy/200916/MatMon092291HS2011StuMur_LR_20702_1 .pdf

Mutendi, M., \& Makamure, C. (2019). The Role of Written Feedback in Numeracy in the Primary School Classroom. International Journal of Education, 11(2), 52-67. https://doi.org/10.5296/ije.v11i2.14550

National Council of Teachers of Mathematics (NCTM) (2000). Principles and Standards for School Mathematics: An Overview. Reston.

Nazihatulhasanah, A., \& Shukor, N.A. (2015). The effects of GeoGebra on students' achievement. Procedis-Social and Behavioral Sciences, 172, 208-214. https://doi.org/10.1016/j.sbspro.2015.01.356

Nziramasanga, C. T. (1999). Zimbabwe Report of the Presidential Inquiry into Education and Training to His Excellency, The President, Harare: Government Printers.

O'Malley, P. (2010). Students evaluation: Steps for creating teacher-made test. Paper presented at Assessment Group Conference-School programme, Maryland, Kennedy Krieger Institute.

Ogwel, A. (2009). Using GeoGebra in Secondary School Mathematics Teaching. ICT in the Classroom Conference. Durban Girls' College: September 24-26, 2009. 
Pleet, L. J. (1990). The effects of Computer Graphics and Mira On Acquisition of Transformation Geometry Concepts and Development of Mental Rotation Skills in Grade Eight. Los Angeles: Oregon State University.

Reis, Z. A., \& Ozdemir, S. (2010). Using Geogebra as an information technology tool: Parabola teaching. Procedia-Social and Behavioral Sciences, 9, 565-572. https://doi.org/10.1016/j.sbspro.2010.12.198

Seloraji, P. \& Eu, L. K. (2017). Students' Performance in Geometrical Reflection Using GeoGebra. Malaysian Online Journal of Educational Technology, 5(1), 65-77.

Shadaan, P., \& Eu, L. K. (2013). Effectiveness of Using GeoGebra on Students' Understanding in Learning Circles. The Malaysian Online Journal of Education, 1(4), 1-11.

Soon, Y. (1989). An investigation of van Hiele-like levels of learning in transformation geometry of secondary school students in Singapore (Unpublished Doctoral Dissertation), The Florida State University.

Stols, G., \& Kriek, J. (2011). Why Do not All Maths Teachers Use Dynamic Geometry Software in Their Classrooms? Australian Journal of Educational Technology, 27(1), 137-151. https://doi.org/10.14742/ajet.988.
Vasquez, D. E. (2015). Enhancing student achievement using GeoGebra in a Technology Rich Environment (Masters Thesis), Faculty of Science, Department of Mathematics and Statistics, California State Polytechnic University, Pomona.

Wesslem, M., \& Fernandez, A. (2005). Transformation Geometry. London: King's College.

White, H., \& Sabarwal, S. (2014). Quasi-experimental design and methods: methodological briefs, impact evaluation No. 8. Unicef Office of Research, Innocenti.

Zengin, Y., Furkan, H., \& Kutluca, T. (2012). The effect of dynamics mathematics software GeoGebra on student achievement in teaching of trigonometry. Procedia Social and Behavorial Sciences, 31, 183-187. https://doi.org/10.1016/j.sbspro.2011.12.038

Zimbabwe school Examination Council (ZIMSEC) (2004-20018). 'O' level mathematics Syllabus 4008/4028, CDU: Harare. 